\title{
Vulnerability and the Consenting Subject: Reimagining Informed Consent in Embryo Donation
}

\author{
Rebecca Hewer $^{1}$ \\ Published online: 14 November 2019 \\ (c) The Author(s) 2019
}

\begin{abstract}
Informed consent is medico-legal orthodoxy and the principal means by which research encounters with the body are regulated in the UK. However, biomedical advancements increasingly frustrate the degree to which informed consent can be practiced, whilst introducing ambiguity into its legal significance. What is more, feminist theory fundamentally disrupts the ideologically liberal foundations of informed consent, exposing it as a potentially inadequate mode of bioethical regulation. This paper explores these critiques by reference to a case study-embryo donation to health research, following fertility treatment, as regulated by the HFEA 1990 - and contends that informed consent cannot adequately respond to the material realities of this research encounter. Thereafter, by drawing on feminist theories of vulnerability, this paper proffers an alternative bioethical approach, which calls for structural reform in recognition of the fundamentally bilateral constitution of self and society and a renewed appreciation for the affective/dispositional tenor of lived experience.
\end{abstract}

Keywords Informed consent · Bioethics · Vulnerability · Embryo donation · HFEA 1990

\section{Introduction}

The problem with informed consent (IC) is that it is premised on a political fiction. Feminists have long problematised IC's reliance on the asocial subject of liberalism: demonstrating the embodied and embedded character of subjecthood and querying IC's capacity to safeguard health-research participants (Corrigan 2003; Ells 2003; Faden and Powers 2011). Moreover, biomedical advancements place increasing strain on the practice of IC, even when its founding (liberal) principles are

Rebecca Hewer

rebecca.hewer@ed.ac.uk

1 Centre for Biomedicine, Self and Society, University of Edinburgh, 23 Buccleuch Place,

Edinburgh EH8 9LN, UK 
countenanced (Caulfield 2007; Taylor 2008). Despite this, IC is a bioethical orthodoxy and a principal method by which UK law regulates research encounters with the body (Laurie and Postan 2013). And whilst a rich feminist scholarship meaningfully complicates understandings of, and reliance on, IC, a sizable proportion continues to treat the fictitious subject of liberalism, and the bioethics it justifies, as worthy of emulation. IC therefore resists more radical bioethical reformulations.

I endeavour to push past this resistance. I do so by building on extant feminist scholarship to critically engage with the UKs regulatory reliance on IC and the ethical encounters it putatively mandates. In turn, I offer an alternative bioethical model, underpinned by feminist theories of 'vulnerability' (Butler 2016; Fineman 2008; Rogers et al. 2012). This 'vulnerability model' treats autonomy as fundamentally unattainable and IC as an inadequate regulatory technology. In deference to the productive and bilateral relationality which exists between individuals and their communities, it demands extensive structural reform. The 'vulnerability model' therefore calls for the 'individual' to be de-centred in bioethical regimes. It does not do so, however, by embracing paternalism. Rather it requires consent practices which recognise the epistemic standing of the subject in deference not to her autonomy, but to her expertise in the affective and cognitive experiences of her particularised embodiment.

The 'vulnerability model' eschews procedural approaches to bioethics, necessitating a consideration of context. Indeed, implicit in my critique of IC is the contention that ethics cannot be procedural in nature, as proceduralism is intelligible only when we accept the salience of an abstract subject. Abstraction, I demonstrate, denies the social reality of embodiment, subsequently hindering resistance to inequality, subjugation and harm. Accordingly, this paper draws on a substantive case-study: the regulation of embryo donation to health-research, following fertility treatment.

I begin, below, by considering the theory, legal codification and genealogy of IC. By situating IC in its socio-historic context, I demonstrate its political contingency and highlight its limitations. Thereafter, I explore how biomedical advancements have frustrated, and continue to frustrate, the practice of IC-even when its ideological precepts are countenanced. I then explore feminist readings of IC before drawing these critiques together in an interrogation of a case-study: embryo donation to health research. In the latter half of this paper, I introduce socio-legal and queer feminist theories of vulnerability, and explore how they can be deployed as a heuristic-framework, apt to reconceptualise bioethical norms. I conclude by returning to my case-study to explore how a vulnerability analysis might shape the way we understand and respond to embryo donations to health-research.

\section{Informed Consent}

Dominant models of IC are founded on liberal conceptions of 'subjecthood' (Ells 2003). Liberalism posits an essentially disembodied, rational and asocial individual who, in the right circumstances, is able to choose and act in ways which reflect their autonomous desires (Mackenzie and Stoljar 2000). Accordingly, IC is organised around the moral stipulation that autonomous decision-making be facilitated 
and respected. Materially, this involves the satisfaction of three 'threshold criteria'. IC must: be granted voluntarily; by someone who has capacity; and subsequent to the consideration of salient information (Beauchamp and Childress 2013). Accordingly, in biomedical research, IC is said to occur when an autonomous subject, ostensibly acting alone, makes an explicit authorisation to a clinician or researcher, following careful consideration of adequately comprehensive research information (Beauchamp and Childress 2013; Ells 2003). This authorisation permits researchers to encroach on the bodily integrity of a subject, or use their tissue/data, without incurring the ethical, civil or criminal liability which would arise if consent were not sought (Keywood 2000).

This model of IC is bioethical and medico-legal orthodoxy across the West, reflecting the centrality of liberal thought in the same region (Corrigan 2003; Sisti and Stramondo 2015). As Laurie and Postan (2013) demonstrate, a legal requirement to obtain spoken or written consent is established by much UK/EU legislation regulating biomedical research (e.g. the Human Tissue Act 2004, the Data Protection Act 1998) and, very frequently, this consent must be informed. For instance, the Medicines for Human Use (Clinical Trials) Regulation $2004^{1}$ states that consent must be "given freely after [a] person is informed of the nature, significance, implications and risks of [a clinical] trial".

Historical narratives regarding the dominance of informed consent are wellrehearsed (Caulfield 2007; Chelouche 2005; Corrigan 2003; Faden and Powers 2011) and arguably amount to an 'origin story', e.g. an account of how IC acquired its current form, which functions as a benchmark for the consideration of contemporary challenges (Dingwall 2016). Perhaps the historic document most frequently cited in this narrative is 'The Nuremberg Code' (1947), drafted in response to the violence of Nazi doctors against the bodies of primarily Jewish prisoners, in the name of 'science' (Chelouche 2005; Corrigan 2003). Whilst the Code contains ten principles, the first declares, that "voluntary consent of the human subject is absolutely essential". Beyond this, a series of historical scandals are routinely invoked to justify a continued commitment to IC (Caulfield 2007; Chelouche 2005; Faden and Powers 2011). One such case is the 1932 Tuskegee Syphilis Trials held at Tuskagee University, Alabama, USA: 408 black male syphilis sufferers, were told they had 'bad blood' and subsequently offered 'treatment'. In truth, the men were part of a covert study of untreated syphilis and doctors were strategically withholding treatment (Chelouche 2005). This scandal occurred, Caulfield (2007) and Chelouche (2005) argue, at least partially because properly informed consent was not sought.

Another case similarly attracting continued attention is that of Henrietta Lacks (Faden and Powers 2011). In 1950, Lacks - a poor black woman living in racially segregated America-unknowingly donated cells to research. These cells, taken from Lacks' highly malignant tumour, without her consent, "gave rise to an enormous advance in biomedical science" (Faden and Powers 2011, 596). Lacks' cells birthed the first immortal human cell line (HeLa), which latterly contributed to multiple biomedical advancements including the polio vaccine. Lacks died shortly

\footnotetext{
${ }^{1}$ Paragraph 3 to Part 1 of Schedule 1.
} 
after her cells were taken, and likely knew nothing of their impact. Her family-who remained largely poor and unable to access consistent, high quality healthcarewere only made aware of Henrietta's global influence well after her death. Faden and Powers suggest that in reflecting on this case, the importance of self-determination becomes clear. They posit, however, that valid self-determination can only take place in favourable social conditions, e.g. those in which the self-determining subject is "not merely the instrument... of social forces that she has had no role in shaping" (Faden and Powers 2011, 599). The authors thus problematise the failure to obtain Lacks' consent and the context within which such failure occurred (i.e. systemic racism). They subsequently eschew individualistic proceduralism in favour of a more contextual approach.

It is well established that dominant models of IC grew up in response to, and solidified subsequent to, scandal: canonical cases in which explicit authorisation was not sought and autonomy was violated (Azétsop and Rennie 2010). But these cases can be read differently, IC was not born of inevitability: each scandal involved some level of biomedical complicity in oppressive regimes which harmfully marginalised a subsection of society. In the case of the interned Jews and black men of Alabama, this complicity is clear-with little respect at best, and hatred at worst, bodies were harmed, lives were risked and lost, and medical 'advancements' were built on the suffering of an underclass. In Lacks' case, this complicity is less direct but egregious nonetheless: a biological resource was taken from a black woman to secure health for a society that systematically failed (and fails) to support black women, their families and their communities. In all cases, a racist lack of deference for human wellbeing played a significant role, and it is not clear that IC could ever have shouldered the resulting (bio)-ethical load. As Faden and Powers (2011) contend, had Lacks consented, grievous wrongs would nonetheless have been committed.

Beyond this, IC has received sustained criticism on two grounds. First, whether IC, taken on its own ideological terms, continues to be an appropriate way to regulate all biomedical research practices is contentious. Second, the question of whether we should take IC on its own ideological terms is contested. Below, I consider both critiques, before applying them to a case-study: the regulation of embryo donation to health-research, following fertility treatment.

\section{Biomedical Advancements}

Advancements in biomedical research make it increasingly difficult to satisfy the threshold criteria of IC, particularly the informational criterion (Caulfield 2007; Taylor 2008). These advancements also complicate IC's socio-legal significance, in practical if not symbolic terms (Laurie and Postan 2013). Illustratively, there is a growing recognition that the complexity of scientific endeavour, and the level of scientific literacy required to understand much biomedical research, constrains the degree to which average research participants can be considered adequately 'informed' (Corrigan 2003). Biobanks provide another compelling example. When biological materials become constituent fragments of a biobank resource, they facilitate otherwise unfeasible biomedical enquiry. However, because biobanks function 
as research platforms - utilised iteratively over time by multiple actors pursuing distinct research agendas - it is not possible to secure truly informed consent at the time of donation. Where IC is mandated, it must be sought by each individual research project (Caulfield 2007; Caulfield and Kaye 2009). This process of iteratively seeking consent has been framed as expensive, administratively fraught (Caulfield and Kaye 2009; Taylor 2008), and prohibitive. Consequently, many biobanks, including the UK Biobank, rely on broad consent, via which donors permit the use of their tissue/data in a broad range of otherwise undefined health-research endeavours (Caulfield and Kaye 2009).

Whilst the use of broad consent is permitted, in particular circumstances, by the Human Tissue Act 2004, Caulfield and Kaye (2009) contest this development, positing that justifications for the utilisation of broad consent (e.g. cost and administrative burden) lack reasoned foundation, providing limited defence for ethically significant change. They argue that proper IC should be sought from biobanks, regardless of the challenges. In contrast, theorists like Taylor (2008) support this turn to broad consent, arguing that it adequately protects participants' wellbeing, and should be embraced in the interests of the "public good'. "Consent issues will endanger research into rare diseases" Taylor $(2008,32)$ claims, "we cannot simply demand the benefit and decline the cost [of health-research]... living ethically requires considering the interests of others as well as one's own" $(2008,32)$. By suggesting subjects entertain an obligation to 'the public', Taylor clearly challenges the ethical foundations of liberal regulatory regimes (Caulfield 2007). He does so, however, in contrasting terms to Faden and Powers: for whilst Taylor claims the subject has a responsibility to society, Faden and Powers focus on society's responsibility to the individual.

Beyond this, it is increasingly unclear what role IC plays in the legal protection of research participants. Though, as discussed, UK health-research regulation frequently mandates IC, Laurie and Postan (2013) demonstrate legal ambivalence regarding what remedy participants might claim in the event of consent vitiation. Illustratively, in cases in which tissue is donated and used in ways contrary to the terms of consent, it is unclear what (if any) legally recognisable harm befalls them [e.g. a kind of harm for which legal remedy can be sought (Laurie and Postan 2013)]. This is broadly reflective of prolonged uncertainty regarding what interest an individual maintains in material extracted from their body (Perley 1992). There is some evidence to suggest that the UK courts are willing to consider violations of autonomy as a form of actionable harm, but this is by no means established precedent (Keren-Paz 2019; Laurie and Postan 2013). Thus, whilst breaches of consent may result in sanctions for researchers, the legal position of the donor is ambiguous at best. This ambiguity has prompted Perley (1992) to advocate for the legal recognition of dignity as a violable interest, and Laurie and Postan (2013) to encourage an increased focus on the development of trust between participants and researchers.

What these brief examples illustrate is that the materialities of health-research, and its traditional regulation through law, can frustrate the proper implementation, and/or utility, of dominant models of IC. Next, I explore critiques of IC that postulate the model would remain ethically suspect even if these significant challenges were overcome. 


\section{Fundamental Critiques of Informed Consent}

Feminist critics have long expressed scepticism regarding the liberal subject. Liberal notions of selfhood, they posit, erase the manifold relationships which not only make a life possible, but constitute that life (Ells 2003; Sisti and Stramondo 2015). Liberal subjecthood "underestimates the impact of society, culture and environment" (Azétsop and Rennie 2010, 3). This fixation with the unencumbered subject is, critics contend, an artefact of masculine ideology: naturalising and venerating masculine life, whilst denigrating that which is conceived to be distinctly feminine (e.g. dependency) (Jaggar 1991). Subsequently, a multitude of feminist theorists have posited a social conception of the self-one which acknowledges the relational nature of existence, and recognises the subject as constrained by and/or constituted through dependency (Azétsop and Rennie 2010; Ells 2003; Meyers 2010; Sisti and Stramondo 2015). Relatedly, feminist theorists frequently call for recognition of embodiment, rejecting the Cartesian dualism often endemic to liberal conceptions of rationality (Assiter 2013), and argue that knowledge derived of dependency, emotionality and positionality be treated as epistemically significant (Jaggar 1991). Accordingly, many have argued that the threshold criteria of IC are difficult (if not impossible) to satisfy (Azétsop and Rennie 2010; Ells 2003; Sisti and Stramondo 2015).

Influential social relationships can be understood as both proximate (e.g. mesosystemic) and distal (e.g. macrosystemic) - the former indicating an immediate, interpersonal relationality and the latter a more structural form of connectedness. I raise this, as I wish to acknowledge the material and experiential differences of each, as well as their inherent interrelation. With regard to the former, the material experience of an interaction between a subject (e.g. a researcher) and an object (e.g. a research participant) will differ qualitatively from the experience of a structurally mediated phenomena (e.g. poverty) (Fricker 2007). With that said, mesosystemic relationships are situated in, and shaped by, macro-systems. This is clearly the case with legislatively mandated practices (e.g. informed consent), but remains true of more socio-politically mediated encounters-both structures are implicated in the relationship between researcher and participant. Any distinction is therefore useful primarily because it captures something about the embodied experience of social relationality, rather than because it reflects a straightforward binary.

The proximate relationships of interest within health-research are often those between health researchers and participants, though clearly other salient clinical and personal relationships are of significance. A wealth of research has demonstrated that non-coercive health-research/medical spaces can be imbued with power, in ways apt to create dynamics of dominance and subordination (Corrigan 2003; Dixon-Woods et al. 2006; Ells 2003). Corrigan (2003), Cox (2000), and DixonWoods et al. (2006) demonstrate that participants/patients often defer to the medical expertise of clinicians, either because they trust in their superior scientific knowledge, or because they feel it necessary to be obedient in the face of a status-conferring positionality. Such findings undermine the belief that patients/participants are primarily self-determining subjects, and therefore destabilise the foundational tenets of IC. This work can also be read as demonstrating the structural embeddedness of 
proximate relationships: conceptions of expertise are shaped by epistemic economies in which some perspectives (e.g. medical) are given more weight than others (Fricker 2007). Beyond this, Corrigan highlights the potentially positive dimensions of relationality, arguing that a patient distressed by illness might sincerely wish to defer to loved ones for assistance in decision-making, but be prevented from doing so by mandated consent practices. Thus IC is implicated in undermining patient/ participant wellbeing. This argument illustrates both the limitations of IC and the normative ambivalence of relationality-influential relationships are inevitable, and their desirability varies according to their materiality and consequences.

Distal relationships also play a constitutive role in subject perspectives and positionality. Corrigan posits that narratives of health (research) - propagated primarily by the media-influence the way subjects think through and experience related issues. More broadly, Azétsop and Rennie (2010) posit that subjects living in low- and middle-income countries - characterised by poverty, health inequalities, and underdevelopment-may experience autonomy as so curtailed as to render it functionally non-existent in certain health-care settings. In concert with Faden and Power, Azestop and Rennie suggest that meaningful self-determination can only take place in facilitative social conditions, often secured via macro-systemic reform. This is a position most persuasively articulated by relational autonomy theorists like Meyers (2014), Sisti and Stramondo (2015) and MacKenzie and Stoljar (2000), who offer an alternative account of autonomy as a complex and socially constituted capacity, embedded in our conditions of existence, and made possible by our relationships. Beyond this, many relational autonomy theorists would argue that relationality can cause subjects to develop cognitive frames which reflect hegemonic ideals, rather than their authentic selves. Where the internalisation of such ideals sustains systems of domination, it constitutes 'oppressive socialisation', which damages a subject's autonomous capacities, often leading to complicity in her own subjugation. For the most part, and as before, relational autonomy theorists posit that attention should be paid to the conditions within which consent is practiced. In addition, Meyers (2014) recommends that oppressed subjects be supported to develop critical, creative and introspective capacities which nurture independent thought and the expression of personal desire.

What is notable about relational autonomy theorists is that, whilst they eschew liberal individualism in favour of a more sophisticated treatment of context and relationality, they tend to reaffirm autonomy as a morally central consideration (albeit one amongst others), subsequently reinforcing its bioethical dominance. This reaffirmation of autonomy, I would argue, is the consequence of a seeming desire to return participants to a more genuinely autonomous state, albeit often through structural reform. To illustrate, Meyers expresses a desire to help oppressed subjects engage in "individualising processes" which enable them to develop "agentic skills" (Meyers 2014 , 434). In sum, morally desirable conditions are frequently framed as those which - through attention to relationality-bring the subject as close to dimensions of the liberal ideal as possible. Many critical social theorists would contest this continued - albeit complicated-commitment to the autonomous individual, however, theorising a subject fundamentally constituted by the social (see Bourdieu and Wacquant 1992; Butler 2016). Illustratively, Ells (2003) problematises IC by reference 
to Foucauldian conceptions of the self, arguing that consenting subjects internalise power dynamics and subsequently practise self-surveillance to ensure their embodiment meets social 'norms'. Medical spaces are contexts of disciplinary surveillance, in which the normalising gaze of the doctor-tasked with observing and evaluating the 'sick' - is internalised and performed through the actions of the patient. Patients are not merely forced to confront the power of their clinicians, but are constituted through such confrontations. Importantly, the constitutive dimensions of power are unavoidable: "We cannot dissociate ourselves, even theoretically, from... relationships to make the sort of moral choices that proponents of the liberal view envision" (Ells 2003, 213). There is no 'authentic' autonomous self per se-the liberal subject is a political fiction, the promotion of which conceals both the sociality of the self and the systems of dominance sociality can perform. Consequently, Ells argues, IC becomes "an ideological cover to the political technology of the body" $(2003,221)$.

This section, and the last, demonstrate the importance of substance and indicate that an ethically robust approach to consent should be achieved via an exploration of the sticky, fleshy, concrete matter of existence, e.g. embodiment, relationships, power. If we take feminist critiques of autonomy seriously, procedural approaches to ethics should be eschewed in favour of more context specific approaches. In deference to this observation, I am keen to consider a case-study, which provides a particularised example of how biomedical advancement, the legal codification of IC, and social context constitute spaces of consent, as well as the consenting subject. In what follows, I consider consent through an exploration of embryo donation to health research, by people who have undergone fertility treatment.

\section{Embryo Donation}

In the UK, embryo donation to health-research is regulated by the Human Fertilisation and Embryology Act 1990 (HFEA 1990), as amended (principally by the HFEA 2008), and monitored by the Human Fertilisation and Embryology Authority (HFEA). The HFEA 1990 adopts a permissive approach to health-research: only a handful of experimental activities are prohibited (Fox 2009; Scully et al. 2012). Acquisition of, and work with, human embryos is permitted, subject to an HFEA license and the written consent of embryo donors. In practice, embryos can be sought from donors wholly for research purposes, and from donors who have surplus embryos following fertility treatment (e.g. IVF). The latter provides a particularly potent case for analysis, insofar as it illuminates the myriad social realities and embodied experiences which can contextualise and inform participation in particular forms of biomedical research.

In its regulation of fertility treatment, the HFEA 1990 is organised around two central tenets: consent and child welfare (Fox 2009). Embryo production for in vitro fertilisation requires consent from both gamete donors, as does any subsequent usage thereafter (e.g. donation), and that consent must be informed: Paragraph 3 of Schedule 3 of the Act mandates that 'before a person gives consent....he must be provided with such relevant information as is proper'. With regard to child welfare, clinicians are obliged to consider the wellbeing of any potential child resulting from fertility 
treatment, and offer/withdraw services accordingly (Fox 2009; Keywood 2000). Prior to amendment, the HFEA 1990 required that clinicians consider the presence of a father in evaluating child welfare. This provision-widely judged both sexist and homophobic - has been repealed, but the law continues to reify heteronormative models of parenthood (e.g. permitting the legal recognition of up to only two parents) (Fox 2009; McCandless and Sheldon 2010a). This is the regulatory framework encountered by many donors prior to their involvement in health-research: one that both mandates IC, and provides the context within which IC is sought.

The material realities of embryo production represent an immediate (and particular) challenge to a threshold criterion of IC, namely voluntariness. Two (or more) donors are required to produce an embryo, and both must consent to its use. This is, for the most part, not true of other forms of tissue donation. Pursuant to the HFEA $1990,{ }^{2}$ if - following embryo production, and prior to its use in treatment - one party withdraws their consent to IVF, or refuses donation to health-research, this functions as a 'veto' (Fenton et al. 2010). This principal was confirmed in the case of Evans $v$ The United Kingdom (2008). ${ }^{3}$ The claimant, Miss Evans, wished to undergo IVF using embryos created with her (former) partner, Mr Johnston. Evans was prohibited from doing so, however, because Johnston withdrew his consent. This despite the fact that: ovarian cancer had rendered Evans incapable of producing more eggs, the embryos represented the only chance she had of a biologically related child, and Johnson knew this would be the case when Evans' eggs were inseminated. The HFEA 1990 can thus work to undermine, rather than elevate, autonomy, negating the enactment of a donor's expressed desire.

Contrastingly, some embryo co-producers may adopt deliberative approaches to consent - an eventuality for which there is no provision in law. It is, of course, possible for gamete donors to act alone-consenting (or not) in relative isolation. Indeed, this is often so with anonymous donors. However, many gamete donors will be intimately entwined and plan to parent together. It is therefore reasonable to assume that they might develop feelings, or practices, of shared responsibility. Under a relational autonomy approach, this eventuality is normatively ambivalent. Intimate relationships may provide a context of supportive dialogue, in which a collaboratively desired course of action can be identified. In this scenario, relationality would maximise, rather than diminish, autonomy. Conversely, intimate relationships may be marked by power dynamics, productive of dominance and subservience, via coercive or insidious means. Feminist explorations of heterosexual relationships commonly reveal gendered power dynamics which materially and symbolically position men and women in less than egalitarian terms (Mooney 2000). Inequality of this kind may create a context within which consent negotiations are problematic and the law has no provision for this eventuality. Indeed, liberal regulatory regimes (heavily premised on the privatisation of 'domestic' life) lack the tools necessary to address collaborative consent.

\footnotetext{
2 Paragraph 4 of Schedule 3.

3 EHHR 34.
} 
The HFEA 1990 may do more than oversee (or ignore) autonomous practices. As Carol Smart (1990) argues, the law and its practice produce a particularly powerful (phallocentric) form of knowledge which can work on and through the subject. In short, the HFEA 1990 may subjectify. As intimated, the HFEA 1990 empowers clinicians to assess whether granting IVF treatment would be in the best interests of any resulting child. The attendant 'Code of Practice' mandates that clinics have "documented procedures" $(2017,94)$ to ensure a child's best interests inform treatment decisions, and requires that staff take a "medical and social history" (2017, 95) from potential parents. As intimated, the HFEA 1990 only permits the recognition of up to two parents, appearing to favour a heteronormative dyad over less traditional family forms (McCandless and Sheldon 2010a, b). It may subsequently naturalise certain normative assumptions, requiring their realisation through performance, surveillance and exclusion. Moreover, the National Institute for Clinical Excellence (NICE 2013) guidelines advise that NHS clinics selectively screen patients for treatment according to their age, health behaviours and reproductive histories. Accordingly, many find themselves dependent on private provision (if they can afford it). Thus, those donating embryos have often undergone a powerful filtering process in which certain dimensions of their biological and social lives have been judged as making them more or less deserving of assistance. Insofar as this process casts a normalising gaze, complicit in the constitution of an embodied bio-politics, it is apt to shape subjectivities. Indeed, extant research indicates that paying for fertility treatment can induce a commercial attitude towards bio-value, creating a disinclination towards donation without remuneration (Scully et al. 2012). Moreover, some donors view embryos as (potential) 'babies' (Mitzkat et al. 2010), a framing potentially rendered more intelligible by mandating parenting evaluations prior to fertility treatment. As such, the HFEA 1990 does more than simply mandate consent; it shapes who is prevailed upon to consent and the journey they take to get there. It may therefore substantively shape the experience and outcome of consent processes. ${ }^{4}$

Similarly notable is the HFEA 1990's failure to pay regard to the sexed embodiment of donors (Keywood 2000). As Fenton et al. (2010) observe the HFEA 1990 takes an equivalency approach to sperm and egg donors, treating them as interchangeable with regard to consent. This position fails to recognise the distinct embodied experiences of infertility and gamete production. To illustrate, women (and other egg-producing people) are at a particular disadvantage when it comes to 'future-proofing' their reproductive lives. The physical labour required to produce gametes is significantly more onerous for egg producers than sperm producers (France Jr and Baruffi 2002), and whilst sperm can be frozen, the technology for egg freezing was-until very recently_considered experimental. Women (and

\footnotetext{
${ }^{4}$ Only a very limited body of empirical data is available regarding the experience of patients who consent to the production of embryos and it primarily draws from data generated in other jurisdictions (de Lacey 2007; Millbank et al. 2017; Scully et al. 2012). More research is needed into patient/donor experiences of consent as regulated by the HFEA 1990. Here I focus on inferences drawn from case law and legislation.
} 
other egg-producing people) have therefore often been advised to freeze fertilised eggs (e.g. embryos). The potential injustices of this are aptly demonstrated by Evans $v$ United Kingdom (Sheldon 2004). It is therefore inappropriate to treat potential parties to donation as a-gendered, disembodied and, subsequently, as procedurally interchangeable. By relying on liberal conceptions of the subject-blind to power, the body, and context - the HFEA 1990 arguably disadvantages women. This is the context in, and through, which health-researchers prevail upon donors to donate embryos.

\section{A New Paradigm: Vulnerability}

Thus far, I have discussed IC and its limitations, as well as a range of critiques which query its suitability, and undermine its ideological foundations. I have explored these issues via the specificities of a case-study, namely the donation of (surplus) embryos to health-research. Below, I build on and move beyond this body of work. I do so by drawing on theories of vulnerability to articulate and promote an alternative bioethical perspective. Vulnerability theories are well-suited to this task: they provide a direct challenge to abstraction, liberal subjecthood, and the moral centrality of selfdetermination, by promoting an ethics which attends to the substantive conditions of people's lives. Often rooted in traditions of feminism, theories of vulnerability foreground embodiment, relationality and positionality, and provide a compelling way to 'think-through' bioethical challenges.

Interrelated theories of vulnerability are articulated across an array of disciplines, including socio-legal studies (Fineman 2008; Fineman and Grear 2013) queer feminism (Butler 2016), human geography (Philo 2005) and bioethics (Rogers et al. 2012). In this and subsequent paragraphs, I primarily draw on the work of sociolegal theorist Fineman (2008) and queer feminist Butler (2016).

\section{Theory of Vulnerability}

The central contention of both Fineman and Butler's theses is that vulnerability is universal, an ontology of the body. On the most fundamental level, vulnerability's universality is made evident by the inevitability of human mortality and susceptibility to illness and harm. The vulnerable subject is therefore an embodied subject (Assiter 2013). This embodiment renders the subject inherently relational: dependent on a range of willed and unwilled externalities (Gilson 2011). Communicable disease provides a particularly visceral example of this: unavoidable proximity to unwell others, and unwilled contagions, render us all, without exception, susceptible to harm (Azétsop and Rennie 2010; Rogers et al. 2012). We are endlessly confronted with a world we did not make, may not want, and cannot entirely control. The relationships and dependencies created and necessitated by vulnerability should not, however, be conceived as inherently negative. Rather their normative value should be judged by the work they do (Butler 2014; Gilson 2011). Loving care and its desirable outcomes are responses to, and experienced through, vulnerability. Vulnerability is, therefore, less a delimiting trait and more a radical openness which shapes 
our somatic, sensory, affective, and epistemic capacities (Gilson 2011). In turn, vulnerability creates a moral imperative to move past abstractions and pay attention to the substance and quality of the many and varied relationships which make (a) life possible.

Despite vulnerability's universality, vulnerable subjects are not equivalent. Embodiment and dependency particularise the subject, insofar as bodies, their needs, and their relationships, differ. Thus, whilst vulnerability is an ontological state, its materiality and intensity oscillate across and within populations. The vulnerable subject is therefore positioned. Clearly, embodiment and positionality are constituted through, and constitutive of, social categories of distinction, e.g. gender, ethnicity and class. It is therefore unsurprising that certain material realisations of vulnerability commonly manifest in subpopulations (e.g. racial or class groups). This framing of subjects, and the populations to which they belong, facilitates a particular conception of inequality. Fineman (2008) explicitly promotes her thesis as a reconceptualisation of the constitution and functionality of inequality. She posits that inequality arises when the many and varied, proximate and distal relationships of the vulnerable subject, asymmetrically intensify or ameliorate their vulnerabilities. To take the example of a contagion, it may be that two bodies are equally susceptible to illness, but not equally able to access healthcare, paid time off work, or family support. This, in turn, demonstrates how both proximate and distal relationships can mediate the intensity and material realisation of vulnerability.

To take a more overtly socio-political example, understanding vulnerability as universal but particularised, as mediated by an array of relationships which asymmetrically intensify susceptibility to harm, is congruent with critical race theory (CRT). According to CRT, racialisation is premised not on some intrinsic distinction between white and non-white populations, but is rather an ongoing and ever changing social process (Ford and Airhihenbuwa 2010). CRT does not deny, however, that racialisation-insofar as it shapes social and institutional relationalities-has material consequences. Racialisation is very clearly implicated in violence, poverty and marginalisation, in ways subsequently ignored via liberal appeals to a colour-blind equality politics (Crenshaw 1991; Ford and Airhihenbuwa 2010). In sum, vulnerability echoes CRT by problematising both claims to intrinsic dominance and the political erasure of material difference (Gilson 2011).

Similarly in concert with critical race theorists, vulnerability theory allows for a multidimensional framing of inequality, insofar as it highlights how highly specified relationalities variously ameliorate and intensify negative life outcomes. In sum, vulnerability theories are intersectionally disposed (Cho et al. 2013). What this means in practice is that the recognition of vulnerability-like the recognition of intersectionality-disrupts univariate analyses of disadvantage (e.g. racism, classism) and facilitates an exploration of how intersecting systems of dominance (e.g. race and class) variously compound or alleviate social harms. Privilege, Fineman (2008) and Crenshaw (1991) explain, can be experienced by those belonging to populations who disproportionately suffer disadvantage. This does not undermine the contention that disadvantage is socially mediated, but rather demonstrates its relative complexity. Relatedly, both Fineman and Crenshaw frame their theoretical offerings as critiques of liberal discriminatory models of equality. Fineman argues 
that these models - which rely on the identification of separate 'protected classes' not only disallow consideration of intersecting (dis)advantage, but ignore important forms of social inequality. Most notably, Fineman posits, they fail to recognise how socio-economic status and/or class-mediated by and mediating relationality - can variously intensify and alleviate the material manifestations of an individual's vulnerability. Vulnerability theses can be used, and have been used, to problematise the intra- and international misdistribution of wealth (Grear 2013; Philo 2005)—framing affluence and poverty as produced through asymmetric relationships to global capitalism.

Clearly, both Fineman and Butler frame vulnerability in ways which diverge from dominant conceptions of the same. Within bioethics, vulnerability is frequently framed as aberrant: a quality of a human subgroup, peculiarly at risk of exploitation and harm, most frequently because of 'reduced capacity' (Rogers et al. 2012). Vulnerability is perceived in liberal terms - a pathological inability to engage in rational thought, rendering the subject impaired with regard to self-determination. Beyond bioethical regulation, vulnerability tends to carry similar connotations, and is often used to describe particularly marginalised groups (Brown 2014). Selective applications of the term necessarily imply invulnerability is possible-embodied by the seemingly advantaged (e.g. white, wealthy people). As discussed, this framing erases the relational constitution of privilege, and its subsequent contingency (Gilson 2011). Fineman and Butler vehemently contest selective applications, arguing that, when we deny vulnerability's ontological status, we privatise responsibility and mask the social organisation of relationships which shape individual outcomes. Indeed, Fineman (2008) argues that, insofar as vulnerability is produced through, and is productive of, widespread social relationality, it demands an eschewal of privatisation in favour of structural reform. In brief, she argues that the state should proactively distribute assets in a way which equalises the development of resilience against the negative effects of vulnerability. Like Faden and Powers (2011), and Azétsop and Rennie (2010), Fineman calls for an ethical reorientation, from a focus on the individual, to a focus on the social space contextualising the individual. Unlike them, however, Fineman does not reaffirm the fictitious liberal subject and does not primarily aim to secure conditions for self-determination. This is not to say that vulnerability theorists are disinterested in the lived experience of the embodied subject, but rather that autonomy loses its political potency.

Indeed, in fundamentally undermining the liberal subject, vulnerability theses destabilise ethical narratives premised on him. As Butler posits, "the postulation of a generalised precariousness that calls into question the ontology of individualism implies... certain normative consequences" $(2016,33)$. What is more, the embodied particularity of the vulnerable subject precludes ethical theorising organised around an abstracted and universalised self. As intimated, Fineman mandates that states be positively responsive: recognising embodiment and positionality, and seeking to equalise outcomes through structural change. In contrast, Butler identifies a more global obligation-implicating subjects and spaces putatively beyond the reach of the state - to act as if all lives were 'grievable'. I favour a culmination of these positions, one which places primary liability with state actors, whilst necessitating a more socially permeated, sometimes 
individualised, ethics of care (Jaggar 1991). However, whilst I am intrigued by the notion of a global obligation, I agree with Young insofar as she posits that people with power (e.g. state actors) and people "who benefit relatively from structural inequalities" have "special moral responsibilities to correct them" (1990, 18).

Having described the theory of vulnerability and the ethical imperatives it creates, I now wish to discuss how it helps us 'think through' bioethics and consent.

\section{Vulnerability Model}

Vulnerability theses destabilise the foundational tenets of IC and render its threshold criteria untenable. Illustratively, the threshold criterion of voluntariness is undermined by the fundamentally relational subject who's cognitive, affective and dispositional tendencies are shaped socially. The notion of capacity-insofar as it is conceived as a facility for 'rational' thought—is frustrated by embodiment [which renders cognition more than strictly intellectual (Shilling 2001)] and contingent positionality/relationality [which renders knowledge social and situated (Gilson 2011)].

Perhaps more importantly, however, in recognising the myriad ways subjects lack control over their wellbeing, vulnerability theses undermine autonomy's moral centrality in bioethical regulation, and demand attention be paid to the conditions of people's lives. Indeed, by recognising the ultimately situated character of the vulnerable subject-her enmeshment in a complex web of interpersonal and structural relationships which limit and intensify her susceptibility to harm-we illuminate the morally impoverished dimensions of a bioethics which focuses almost entirely on 'autonomy'. This focus both fails to attend to the potentially undesirable context within which subjects are prevailed upon to consent (e.g. racist, sexist, classist contexts) and erases the global obligation to act with care. Vulnerable subjects (insofar as we are all vulnerable) are non-innocent: they are as much depended on as dependent, and obliged to act ethically (though, as intimated, such obligation weighs more heavily on the shoulders of the powerful and privileged).

In deference to this, I contend that we embrace a 'vulnerability model' of bioethics, which attends to the relationality of the subject. However, and as discussed, the lived experience of relationality varies significantly depending on the proximity of any given relationship. Systems of oppression-such as those explored at the beginning of this paper-are sustained through a multiplicity of proximate and distal relationships, and must be resisted in multifaceted ways. Whilst the mal-distribution of resources may sustain racist societies, so too does hate speech. Furthermore, the discourses made manifest in hate speech, and resource inequality, are co-constitutive-creating a context in which weakening one potentially weakens the other. It is therefore necessary to devise bioethical modes of response which can be enacted concurrently and attend to both proximate and distal relationality. As such, and in what follows, I take each in turn. 


\section{Vulnerability and Distal Relationality}

At this juncture, it is valuable to revisit Taylor's (2008) argument regarding a tissue donor's ethical obligation to the public good (above). Taylor argues that "we cannot simply demand the benefit and decline the cost [of health-research] ... living ethically requires considering the interests of others as well as one's own" (2008, 32). In light of my analysis, Taylor's contention appears reasonable: the vulnerable subject has an ethical duty to consider the wellbeing of others and act with care. Taylor's argument fails to address two things, however. First, scepticism regarding the contention that donating one's biological resources will necessarily result in the public good, would seem judicious. Not least because the 'public' is heterogeneous, a collection of subjects with radically different relationalities and-consequently-life outcomes. As we have established, gender, ethnicity and socio-economic status are all complicit in the intensification and amelioration of individual vulnerability-in ways which create distinct patterns of disadvantage across and within populations. Secondly, and relatedly, what Taylor's argument ultimately fails to address is the bilateral character of relationality. In sum, Taylor fails to consider the very real possibility that those he prevails upon to donate tissue for the good of society, may receive disproportionately little of society's goods.

Reconsider the case of Henrietta Lacks. As Faden and Powers (2011) argue, the greatest injustice of Henrietta Lacks' case was not a failure to secure consent, but rather the use of her cells to secure health for a society which marginalised her. The greatest injustice was that Lacks was mined for her biological resources, whilst being treated as if she were not deserving of all the resources society had to give. This denial of bilateral relationality represents an egregious wrong requiring redress. Mainstream society makes itself tall by standing on the bodies of the marginalised. It does so both via a recognition, and disavowal, of vulnerability. This contradictory stance legitimises a (neo)-liberal political order premised on the invulnerable subject (framing individuals as masters of their fate and valuing autonomy above all else), whilst creating institutions (e.g. health-research and pharmaceutical companies) which asymmetrically ameliorate susceptibility to harm. In turn, IC may-inadvertently or otherwise - work as a political technology of sustained inequality.

Indeed, I would posit that subjects should only be prevailed upon to consent to research participation when attention has been paid to inequalities, and remedial action has been taken. Substantively, health-research regulation should consider not merely human donors who make scientific advancements possible, but the societies which make human donors possible. Racist and sexist societies, which support the mal-distribution of resources responsible for the amelioration of vulnerability, are a bioethical concern. And whilst it may not be in the gift of health-research policy-subsystems (see Sabatier 1988) to radically restructure the conditions of social existence (though this should be our aim), it is certainly within their gift to mandate research agendas be informed by a commitment to health inequalities. This is particularly salient given the context of global neoliberalism within which healthresearchers work, in which profit rather than public good may motivate scientific endeavour. 
To clarify, I do not wish to promote a contractarian calculus (to suggest donors should only give as they receive, or receive as they give) nor do I wish to pursue a paternalistic turn. Regarding the former, not only would a calculus be untenable to enact, it would be morally suspect, given how disadvantage can breed distrust in biomedical science. Illustratively, it would be entirely understandable if black people in the United States felt suspicious of health-research, and unwilling to participate in its endeavours, given its repeated complicity in racist oppression (Benjamin 2014). Rather, I would argue that we treat the vulnerability model as a heuristic, which creates an imperative to consider social injustice as a bioethical matter. With regard to the latter, classic portrayals of bioethical regulation place IC in a dualistic relationship with paternalism, in which rejection of one necessarily implies embrace of the other (Corrigan 2003). However, whilst I would advocate for an ethical decentralisation of the individual, I am nonetheless critical of interventions which fail to acknowledge the importance of lived experience. This necessitates a consideration of proximate relationality.

\section{Vulnerable Consent and Proximate Relationality}

In many ways, paternalism is anathema to a vulnerability model of bioethics. Vulnerability's universality renders health researchers as much relationally constituted as their participants. In contrast to theories of relational autonomy, theories of vulnerability do not endorse framings of socialisation as aberrant, e.g. oppressive socialisation. The operationalisation of 'oppression' rendering oppressive socialisation intelligible is totalising (erasing the multidimensionality afforded by vulnerability theses) and denies the fundamentally social nature of the subject. It would be unreasonable to advocate for amelioration of the sociality of participant subjectivity by rendering it subordinate to the sociality of the researcher. If the history of biomedical scandal has proven anything, it is that practitioners are non-innocent in the sustenance of oppressive orders. Indeed, if anything, the universality of vulnerability demands that we critically engage with hierarchy, given the mutuality of our dependency.

What is more, reimagining the subject (and her epistemic capacities) in relational and embodied terms does not require that we treat her wishes as immaterial. This position might be intelligible if we persisted in framing the liberal subject as an attainable ideal, but since it is a political fiction, any veneration would be nonsensical. Rather, I would argue that by acknowledging embodiment, we are bound to acknowledge the necessarily subjective nature of knowledge and subsequently create an ethical imperative to give epistemic weight to the affective, dispositional and cognitive experiences of the subject. This, then, provides grounds from which to both problematise practices which do not adequately respond to such experiences (e.g. paternalism) and to promote practices built around care. Clearly, the latter kind of practices would be dialogic_-the vulnerable subject's particularised embodiment, and positionality, suggest she should be treated as an 'expert' in her own physical and affective wellbeing. To fail to treat her as such would be both coercive and unjust. This, subsequently, creates an imperative to foreground participant 
'voice' (Ford and Airhihenbuwa 2010; Houh and Kalsem 2015)_both by obtaining affirmative consent to research participation and by pursuing more inclusive forms of knowledge production.

Just because, as relational autonomy theorists posit, certain forms of socialisation might assist in the sustenance of oppressive systems and subsequently render coercion largely surplus to requirements, does not mean coercion is evacuated of its oppressive potentialities. The subjugation of women has too frequently been achieved through attempts to control, regulate and act upon their bodies against their wishes (e.g. via abortion laws, rape), and no progressive agenda can be born of replicating these practices. Whilst the social constitution of subjects may play a role in sustaining systems of domination, this cannot be remedied by similarly constituted subjects coercively imposing their will. Doing so, at the very least, creates the proximate injustice of negative affective states (which I propose we take seriously). The lived experience of being ignored and subject to unwilled bodily incursions/ misuse of our tissue can be framed as painful and ethically dubious even when we eschew autonomy as the centre of moral justification, because we can retain a sense of what is experienced and what is felt. As intimated, much injustice is realised at the embodied level: hate speech does not merely contribute to violent discourse, it wounds the subject. Furthermore, the systematic failure to award epistemic credibility to particular subgroups in society, often legitimised by and legitimising prejudicial assumptions regarding credibility (e.g. women are hysterical), creates large scale structural disadvantage — an anathema to the central premise of vulnerability theses.

Finally, whilst the vulnerable subject may be an essentially social phenomenon, she nonetheless retains her specificity. Not only are her needs particular to her, but her socio-historic trajectory is irreducible to the trajectory of another (Bourdieu and Wacquant 1992). It is also important to retain a sense of the vulnerable subject as non-innocent; that is, she is both dependent and possessed of dependants (in the broad sense). In totality, these facets suggest that "people are both subject to power and subjects of power" (Ells 2003, 215). What this means in practice is (a) marginalised knowledge is valuable, (b) that granting or withholding consent to research participation represents a (potentially productive) moment of rebellion, which should not be foreclosed upon, and (c) that knowledge production should be a socially collaborative endeavour. As Gilson (2011) argues, the act of deciding what your vulnerability should look like-by rejecting some forms of relationality and embracing others - can be a form of resistance. It is therefore possible that in retaining consent in its many forms, as a vital dimension of bioethical thought and regulation, we facilitate acts of resistance. Clearly (and as evidenced by the regulation of embryo donation) who is positioned to enact rebellion through consent can be structured through injustice. However, I propose that we embrace localised resistance where we find it, for pragmatic reasons, whilst simultaneously seeking to address the wrongs which limit its potential.

The practice of vulnerable consent (VC) to research participation would involve both ongoing and bounded facets. With regard to the former, $\mathrm{VC}$ could not be, in its totality, considered a one-off event. Rather, clinicians/researchers would be prevailed upon to recognise that ongoing discussions with participants represent an 
integral facet of consent practices, as do the qualitative characteristics of the relationships participants form with proximate others and the institutions housing them. In turn, clinicians/researchers should endeavour to nurture dialogic, warm and caring relationships with participants. However, for clarity and accountability, explicit authorisation should be sought and recorded. The standardisation of consent forms should give way to collaboratively generated documents, detailing the dialogue proceeding a decision to consent. In conducting such dialogues, it will be important to acknowledge the epistemic vulnerability of all parties - that is, the necessarily partial, positional and relational character of knowledge/our capacity to know. Such an acknowledgement requires us to sit with (rather than move away from) uncertainty, ambivalence and discomfort, and to practise a reflexive humility which demands an openness to new information, as well as a commitment to honesty. This, in turn, requires researchers to relinquish their position as subjects to the objects of their participants - as possessors of a verifiable knowledge, gifted in a unilateral exchange to an otherwise empty vessel. Instead, and as previously intimated, researchers must listen to those they prevail upon to consent-must learn their priorities, perspectives, felt needs, and respond appropriately. Thus, there can be no standardised model of what and how much information should be provided to a potentially consenting party, rather this must be discovered iteratively and relationally, with a view to the substantive realities and lived experience of the particularised subject. It may be that one subject requires a detailed description of the research their tissue is intended for, and this should be provided if possible; or it may be that another subject wishes to defer their decision to the doctor, and this too would be acceptable. It must be acknowledged that a person may change their mind, as they are want to do, but that the degree to which this change of mind can be acted upon will differ due to material constraints. And, of course, it must be recognised that this process is imperfect and hard-but that difficulty and imperfection are poor reasons not to try. What is important, here, is not procedural adherence, but rather the substantive treatment and experience of the vulnerable and consenting subject.

There is one necessary caveat to this, and that is that we must remain constantly vigilant to unknown unknowns. That is, a vulnerable subject prevailed upon to participate in research may (by virtue of their social positionality) lack insight into the kinds of knowledge available. What is more, where unknown unknowns are systematically sustained through politics of knowledge production, their continued opacity might perpetuate systemic wrongs (Gilson 2011). We must, therefore, treat the identification of the kinds of knowledge which might be 'salient' as an ongoing, dialogic and collective endeavour. Whether or not VC would significantly change the practice of consent is an empirical question, beyond the scope of this paper. As Azétsop and Rennie (2010) note, whether or not IC is practiced as imagined in clinical decision-making scenarios is not immediately clear-certainly evidence presented by theorists such as Dixon-Woods et al. (2006) and Corrigan (2003) (see above) would suggest that it is not.

Even when we recast consent to research participation in more progressive (and vulnerable) terms, we must continue to acknowledge its limitations. These limitations are, in part, attended to when we pay attention to substantive equality and its structural determinants - as discussed above. However, identifying and defining 
both what constitutes substantive equality and its causes, are fraught processes because substantive inequality has epistemological consequences. In sum, it is near impossible to redress marginalisation with knowledge, if knowledge is as much its potential cause as its potential remedy. Incorporating marginal voices into knowledge production processes has long been a concern of feminists and critical race theorists (Ford and Airhihenbuwa 2010; Lather 1986) — an increasing number of whom are embracing participatory methods (Houh and Kalsem 2015; Ponic et al. 2010). Feminism and CRT share a common commitment to challenging asymmetries in epistemic power and pursuing research which improves conditions for marginalised populations. Participatory Action Research (PAR) similarly supports these aims, and advocates a research praxis fit for such activities. In concert with these theories, I would advocate for participatory and community approaches to (health) research. Of course, biomedical research may remain resistant to a fully participatory methodhowever there is no reason why the public (responsible for biomedicine's raw materials), should not have a say in the direction and substance of its agenda. That is not to say that academic expertise has no place. Rather, that - again - the recognition of a universal epistemic vulnerability is key and that researchers should not "run the show', but rather... bring to the table our own areas of expertise" (Houh and Kalsem 2015,263 ) whilst allowing other vulnerable subjects to do the same.

\section{Vulnerability and the Consenting Embryo Donor}

As intimated, vulnerability necessitates a careful consideration of the embodied and situated contextualisation of practice. Furthermore, acknowledging epistemic vulnerability necessitates the iterative reconsideration of, and (where necessary) challenge to, the fundamental dimensions of the model I propose. Taken together, this means each new substantive 'case' should be considered on its own terms, and viewed as an intellectual and ethical opportunity. Indeed, in exploring embryo donation to health-research via a lens of vulnerability theory, the significant potential and possible limitations of my model become clear.

As discussed, the HFEA 1990 provides a permissive regulatory framework for embryo research-built around the need to obtain IC from (legally equivalent) gamete donors. Adopting a vulnerability model would require significant reform. According to my analysis, we must question the bioethical implications of a society which systematically disadvantages women and then readily avails itself of women's biological resources. This is a particularly potent critique when we consider the asymmetric labour of gamete production (as above). Accordingly, a permissive regulatory approach, which fails to consider the role biomedical research can play in (redressing) women's disadvantage, is putatively unethical. With the advent of human embryonic stem cell research - a biomedical paradigm which could revolutionise the way we understand and approach health (Holland and Caplan 2001) continuing gender inequality takes on an Atwoodian-dystopic hue. An exploration of embodiment facilitates a problematisation of the assumptions of donor equivalency ingrained in the HFEA 1990. As Fineman (2008) posits, this kind of approach fails to account for the sometimes radically different forms of embodiment which 
constitute people's lived experiences. Here, an equivalency approach fails to account for the onerous labour of extracting eggs and asymmetries in how subjects might go about securing their reproductive futures (Fenton 2013; France Jr and Baruffi 2002). This fact was made apparent in Evans $v$ The United Kingdom, in which this major issue was left unaddressed. Embracing a vulnerability model would necessitate critical analysis of this regulatory feature, subsequently creating space for the re-imagination of embodiment in law. Indeed, a vulnerability analysis could well provide the justification for legislative reform which grants women (and other egg-producing people) greater control over their embryos-though this would require more indepth consideration. This, in turn, could fundamentally challenge the 'veto' power of certain parties under the HFEA 1990.

In my previous analysis of the HFEA 1990, I posited that the IC criterion of voluntariness was undermined by the material realities of embryo production, e.g. a context in which gamete donors frequently developed a collaborative interest in their combined materials. Clearly, in drawing attention to the inherently relational subject - and the variously positive and negative dimensions of relationality-vulnerability theory provides a useful lens through which to explore this issue. However, a significant limitation of $\mathrm{VC}$ as presently articulated is that whilst it draws attention to the very real possibility of negative proximate relationships, it does not immediately recommend a form of redress. To compound this concern, if we place value in the constitutive and supportive dimensions of positive relationality, it is possible that we might inadvertently exacerbate the effect of negative relationality, e.g. by failing to adequately differentiate between the two. Given the ubiquity of epistemic vulnerability, and the sometimes insidious forms deleterious control and influence take, it is unclear how adequate modes of differentiation could be achieved. Intuitively, I would suggest space and assistance be afforded to individual subjects, to help them identify the relationality they wish to choose and make this manifest, but this is by no means fail-safe. Similarly, awarding women more control over embryos may go some way to address related issues such as these, but is no panacea. Relatedly, whilst a vulnerability theses may illuminate and affirm the productive role regulatory frameworks like the HFEA 1990 play in shaping positionality and subjectivity, they cannot provide a roadmap for reducing influence. This is because influential distal relationalities such as these are inevitable. Legislation cannot be written in ways which exonerate it from productive, rather than merely regulatory, influence. Instead, more 'favourable' subjectification is necessitated-an observation which poses more questions than it answers. Clearly, further research and analysis is required to understand and address the consent dynamics created by the material realities of embryo production, donation, and regulation. Indeed, in opening up new areas of potential practice, VC illuminates questions liberalism did not know to ask, questions which now require intellectual and ethical scrutiny.

What little research does exist on embryo donation to health-research, following fertility treatment, illuminates something interesting about the lived and embodied experiences of donors. In a series of interrelated research projects exploring embryo donation, Scully et al. (2012) and Mitzkat et al. (2010) found that, when reflecting on their decision to donate to health-research, donors frequently expressed a desire to 'give back' to biomedical science and/or the donors whose donations had made 
fertility treatments possible. These findings echo work on clinical trials (Corrigan 2003; Cox 2000) which similarly indicate that research participation is frequently motivated by a desire to express solidarity with a largely unknown 'other'. Taken together, these findings arguably demonstrate a reflexive appreciation of vulnerability and the situated nature of the self. In turn, they highlight a moral justification produced through, and productive of, positive relational existence. We should take these moral justifications seriously.

\section{Conclusion}

When we acknowledge the inherent sociality of the subject, we are forced to conclude that informed consent is a political technology, built to respond to a political fiction, which it subsequently works to sustain. Placing autonomy at the moral centre of biomedical regulation is ethically questionable, because it licences an ideological erasure of context. 'Relational autonomy' feminists have long problematised this erasure, advocating for structural reform. They have done so, however, in deference to self-determination: pursuing social change in the interests of more fully facilitated autonomous action. They therefore leave prevailing bioethical norms at least partially intact. What is required, I have argued, is a more radical critique of liberalism and a politics which is less interested in making the subject 'free', and more interested in making the subject seen, heard, cared for, and substantively, rather than procedurally, equal. In response to this challenge I have proposed a vulnerability model of bioethics, which draws heavily on the work of Fineman and Butler. This model attends to the constitutive sociality, relationality and embodiment of the subject, by demanding that structural inequalities be treated as a matter of bioethical concern and redressed in deference to our bilateral dependencies. In addition, I have argued that affirmative consent should be sought, not in deference to the moral centrality of autonomy, but rather to the ethical significance of lived experience. Clearly, this model is in its nascent stages of development: more work is required to effectively concretise the recommendations I have made, and answer the questions I have posed. What, then, my vulnerability model provides, at present, is a different vantage point from which to view biomedical challenges, and a new ethical narrative with which to begin addressing them. I have established this potential through a consideration of a case study, namely embryo donation to health research. Indeed, and as I have suggested, a truly progressive 'vulnerability model' of bioethics can only be developed via nurturing an ongoing dialogue between the theory I have articulated here, and the substantive particularities of (biomedical) reality. Only through such work can we truly come to understand the implications and demands of embodiment, relationality and calls for structural reform.

Acknowledgements I am grateful to Graeme Laurie, Mihaela Mihai, Kathy Dodworth and Robert Henthorn for their assistance, feedback and support during the preparation of this article.

Open Access This article is distributed under the terms of the Creative Commons Attribution 4.0 International License (http://creativecommons.org/licenses/by/4.0/), which permits unrestricted use, distribution, 
and reproduction in any medium, provided you give appropriate credit to the original author(s) and the source, provide a link to the Creative Commons license, and indicate if changes were made.

\section{References}

Assiter, Alison. 2013. Kierkegaard and Vulnerability. In Vulnerability, ed. M.A. Fineman and A. Grear, 29-40. Burlington, VT: Ashgate.

Azétsop, Jacquineau, and Stuart Rennie. 2010. Principlism, Medical Individualism, and Health Promotion in Resource-Poor Countries: Can Autonomy-Based Bioethics Promote Social Justice and Population Health? Philosophy, Ethics, and Humanities in Medicine 5 (1): 1.

Beauchamp, Tom L., and James F. Childress. 2013. Principles of Biomedical Ethics, 7th ed. New York: OUP USA.

Benjamin, Ruha. 2014. Race for Cures: Rethinking the Racial Logics of 'Trust' in Biomedicine: Race for Cures. Sociology Compass 8 (6): 755-769.

Bourdieu, Pierre, and Loïc Wacquant. 1992. An Invitation to Reflexive Sociology. Chicago: Polity Press.

British Medical Journal Publishing. 1947. The Nuremberg Code. BMJ 313 (7070): 1448.

Brown, Kate. 2014. Questioning the Vulnerability Zeitgeist: Care and Control Practices with 'Vulnerable' Young People. Social Policy and Society 13 (3): 371-387.

Butler, Judith. 2014. Bodily Vulnerability, Coalitions, and Street Politics. Critical Studies 37 (99119): 247.

Butler, Judith. 2016. Frames of War: When is Life Grievable? Brooklyn: Verso.

Caulfield, Timothy. 2007. Biobanks and Blanket Consent: The Proper Place of the Public Good and Public Perception Rationales. King's Law Journal 18 (2): 209-226.

Caulfield, Timothy, and Jane Kaye. 2009. Broad Consent in Biobanking: Reflections on Seemingly Insurmountable Dilemmas. Medical Law International 10 (2): 85-100.

Chelouche, Tessa. 2005. Ethics and Human Experimentation During the Holocaust: The Rise and Fall of Informed Consent. Health Lawyer 18: 23-30.

Cho, Sumi, Kimberlé Williams Crenshaw, and Leslie McCall. 2013. Toward a Field of Intersectionality Studies: Theory, Applications, and Praxis. Signs: Journal of Women in Culture and Society 38 (4): 785-810.

Corrigan, Oonagh. 2003. Empty Ethics: The Problem with Informed Consent. Sociology of Health \& Illness 25 (7): 768-792.

Cox, Karen. 2000. Enhancing Cancer Clinical Trial Management: Recommendations from a Qualitative Study of Trial Participants' Experiences. Psycho-Oncology 9 (4): 314-322.

Crenshaw, Kimberle. 1991. Mapping the Margins: Intersectionality, Identity Politics, and Violence against Women of Color. Stanford Law Review 43: 1241-1299.

de Lacey, Sheryl. 2007. Decisions for the Fate of Frozen Embryos: Fresh Insights into Patients' Thinking and Their Rationales for Donating or Discarding Embryos. Human Reproduction 22 (6): 1751-1758.

Dingwall, Robert. 2016. Why are Doctors Dissatisfied? The Role of Origin Myths. Journal of Health Services Research \& Policy 21 (1): 67-70.

Dixon-Woods, Mary, Simon J. Williams, Clare J. Jackson, Andrea Akkad, Sara Kenyon, and Marwan Habiba. 2006. Why Do Women Consent to Surgery, Even When They Do Not Want to? An Interactionist and Bourdieusian Analysis. Social Science and Medicine 62 (11): 2742-2753.

Ells, Carolyn. 2003. Foucault, Feminism, and Informed Choice. Journal of Medical Humanities 24 (3/4): 213-228.

Faden, Ruth, and Madison Powers. 2011. A Social Justice Framework for Health and Science Policy. Cambridge Quarterly of Healthcare Ethics: CQ; New York 20 (4): 596-604.

Fenton, Rachel Anne. 2013. Assisted Reproductive Technology Provision and the Vulnerability Thesis: From the UK to the Global Market. In Vulnerability, ed. M.A. Fineman, 125-146. Burlington, VT: Routledge.

Fenton, Rachel, Susan Heenan, and Jane Rees. 2010. Finally Fit for Purpose? The Human Fertilization and Embryology Act 2008. Journal of Social Welfare and Family Law 32 (3): 275-286. 
Fineman, Martha Albertson. 2008. The Vulnerable Subject: Anchoring Equality in the Human Condition. Yale Journal of Law \& Feminism 20 (1): 8-40.

Fineman, Martha Albertson, and Anna Grear. 2013. Vulnerability, New ed. Burlington, VT: Ashgate.

Ford, Chandra L., and Collins O. Airhihenbuwa. 2010. The Public Health Critical Race Methodology: Praxis for Antiracism Research. Social Science and Medicine 71 (8): 1390-1398.

Fox, Marie. 2009. The Human Fertilisation and Embryology Act 2008: Tinkering at the Margins. Feminist Legal Studies 17 (3): 333-344.

France Jr., J.G., and L.R. Baruffi. 2002. Introduction to Methods for Collecting Human Gametes in Assisted Reproduction. Reproductive BioMedicine Online 5 (2): 187-198.

Fricker, Miranda. 2007. Epistemic Injustice: Power and the Ethics of Knowing. Oxford: Oxford University Press.

Gilson, Erinn. 2011. Vulnerability, Ignorance, and Oppression. Hypatia 26 (2): 308-332.

Grear, Anna. 2013. Vulnerability, Advanced Global Capitalism and Co-Symptomatic Injustices: Locating the Vulnerable Subject. In Vulnerability: Reflections on a New Ethical Foundation for Law and Politics, ed. M.A. Fineman and A. Grear, 41-60. Burlington, VT: Routledge.

HFEA. 2017. Human Fertilisation and Embryology: Code of Practice: Code of Practice, 9th Edition.

Holland, Suzanne, and Arthur L. Caplan. 2001. The Human Embryonic Stem Cell Debate: Science, Ethics, and Public Policy. Cambridge, MA: MIT Press.

Houh, Emily M.S., and Kristin Kalsem. 2015. Theorizing Legal Participatory Action Research: Critical Race/Feminism and Participatory Action Research. Qualitative Inquiry 21 (3): 262-276.

Jaggar, Alison. 1991. Feminist Ethics: Projects, Problems, Prospects. In Feminist Ethics, ed. C. Card. Lawrence, Kan: University Press of Kansas.

Keren-Paz, Tsachi. 2019. Gender Injustice in Compensating Injury to Autonomy in English and Singaporean Negligence Law. Feminist Legal Studies 27 (1): 33-55.

Keywood, Kirsty. 2000. "More than a Woman? Embodiment and Sexual Difference in Medical Law." Feminist Legal Studies 8 (3): 319-342.

Lather, Patti. 1986. Research as Praxis. Harvard Educational Review 56 (3): 257-277.

Laurie, Graeme, and Emily Postan. 2013. Rhetoric or Reality: What is the Legal Status of the Consent form in Health-Related Research? Medical Law Review 21 (3): 371-414.

Mackenzie, Catriona, and Natalie Stoljar. 2000. Relational Autonomy: Feminist Perspectives on Automony, Agency, and the Social Self. Cary: Oxford University Press, Incorporated.

McCandless, Julie, and Sally Sheldon. 2010a. 'No Father Required'? The Welfare Assessment in the Human Fertilisation and Embryology Act 2008. Feminist Legal Studies 18 (3): 201-225.

McCandless, Julie, and Sally Sheldon. 2010b. The Human Fertilisation and Embryology Act (2008) and the Tenacity of the Sexual Family Form ${ }^{1}$. Modern Law Review 73 (2): 175-207.

Meyers, Diana. 2010. "Feminist Perspectives on the Self." in The Stanford Encyclopedia of Philosophy, edited by E. N. Zalta.

Meyers, Diana. 2014. Feminism and Sex Trafficking: Rethinking Some Aspects of Autonomy and Paternalism. Ethical Theory and Moral Practice 17 (3): 427-441.

Millbank, Jenni, Anita Stuhmcke, and Isabel Karpin. 2017. Embryo Donation and Understanding of Kinship: The Impact of Law and Policy. Human Reproduction 32 (1): 133-138.

Mitzkat, Anika, Erica Haimes, and Christoph Rehmann-Sutter. 2010. How Reproductive and Regenerative Medicine Meet in a Chinese Fertility Clinic. Interviews with Women about the Donation of Embryos to Stem Cell Research. Journal of Medical Ethics 36 (12): 754-757.

Mooney, Jayne. 2000. Gender, Violence and the Social Order. London: Palgrave Macmillan.

NICE. 2013. Fertility Problems: Assessment and Treatment Guidance and Guidelines. https://www. nice.org.uk/guidance/cg156/chapter/Recommendations\#access-criteria-for-ivf. Accessed 18 February 2019.

Perley, Sharon Nan. 1992. From Control over One's Body to Control over One's Body Parts: Extending the Doctrine of Informed Consent Note. New York University Law Review 67: 335-365.

Philo, Chris. 2005. The Geographies That Wound. Population, Space and Place 11 (6): 441-454.

Ponic, Pamela, Colleen Reid, and Wendy Frisby. 2010. Cultivating the Power of Partnerships in Feminist Participatory Action Research in Women's Health. Nursing Inquiry 17 (4): 324-335.

Rogers, Wendy, Catriona Mackenzie, and Susan Dodds. 2012. Why Bioethics Needs a Concept of Vulnerability. International Journal of Feminist Approaches to Bioethics 5 (2): 11-38.

Sabatier, Paul A. 1988. An Advocacy Coalition Framework of Policy Change and the Role of PolicyOriented Learning Therein. Policy Sciences 21 (2-3): 129-168. 
Scully, Jackie Leach, Erica Haimes, Anika Mitzkat, Rouven Porz, and Christoph Rehmann-Sutter. 2012. Donating Embryos to Stem Cell Research. Journal of Bioethical Inquiry 9 (1): 19-28.

Sheldon, Sally. 2004. Gender Equality and Reproductive Decision-Making. Feminist Legal Studies 12 (3): 303-316.

Shilling, Chris. 2001. Embodiment, Experience and Theory. In Defence of the Sociological Tradition. The Sociological Review 49 (3): 327-344.

Sisti, Dominic, and Joseph Stramondo. 2015. Competence, Voluntariness, and Oppressive Socialization: A Feminist Critique of the Threshold Elements of Informed Consent. IJFAB: International Journal of Feminist Approaches to Bioethics 8 (1): 67-85.

Smart, Carol. 1990. Law's Power, the Sexed Body, and Feminist Discourse. Journal of Law and Society 17 (2): 194-210.

Taylor, Patrick. 2008. Personal Genomes: When Consent Gets in the Way. Nature. https://www.natur e.com/articles/456032a. Accessed 8 October 2018.

Young, Iris Marion. 1990. Justice and the Politics of Difference. Princeton, N.J: Princeton University Press.

Publisher's Note Springer Nature remains neutral with regard to jurisdictional claims in published maps and institutional affiliations. 